\title{
Analysis of Direct Contact Membrane Distillation Based on a Lumped-Parameter Dynamic Predictive Model
}

\author{
Ayman M. Karamª, Ahmad S. Alsaadi ${ }^{\mathrm{b}}$, Noreddine Ghaffour ${ }^{\mathrm{b}}$, Taous Meriem Laleg-Kiratia,* \\ ${ }^{a}$ Computer, Electrical and Mathematical Science and Engineering division (CEMSE), King Abdullah University of Science and \\ Technology (KAUST), Thuwal, KSA \\ ${ }^{b}$ Water Desalination and Reuse Center (WDRC), Biological and Environmental Scinence and Engineering (BESE), King \\ Abdullah University of Science and Technology (KAUST), Thuwal, KSA
}

\begin{abstract}
Membrane distillation (MD) is an emerging technology that has a great potential for sustainable water desalination. In order to pave the way for successful commercialization of MD-based water desalination techniques, adequate and accurate dynamical models of the process are essential. This paper presents the predictive capabilities of a lumped-parameter dynamic model for direct contact membrane distillation (DCMD) and discusses the results under wide range of steady-state and dynamic conditions. Unlike previous studies, the proposed model captures the time response of the spacial temperature distribution along the flow direction. It also directly solves for the local temperatures at the membrane interfaces, which allows to accurately model and calculate local flux values along with other intrinsic variables of great influence on the process, like the temperature polarization coefficient (TPC). The proposed model is based on energy and mass conservation principles and analogy between thermal and electrical systems. Experimental data was collected to validated the steady-state and dynamic responses of the model. The obtained results shows great agreement with the experimental data. The paper discusses the results of several simulations under various conditions to optimize the DCMD process efficiency and analyze its response. This demonstrates some potential applications of the proposed model to carryout scale up and design studies.
\end{abstract}

Keywords:

Dynamic modeling, Direct contact membrane distillation (DCMD), Spacial temperature distribution, Electrical analogy, Heat and mass transfer, Flux predictions, Time response

\section{Introduction}

Membrane distillation (MD) is a hybrid process in which both thermal and membrane separation techniques are combined. In direct contact membrane distillation (DCMD) configuration, hot salty stream passes along one side (the feed side) of a microporous hydrophobic membrane, while on the other side (the permeate/coolant side) of the membrane freshwater passes at a lower temperature. Due to this temperature difference, water evaporates at the feed-membrane interface, and only water vapor passes through the dry pores of a hydrophobic membrane, driven by the saturation vapor pressure differential across the feed and the permeate sides of the membrane. Water vapor

\footnotetext{
${ }^{*}$ Corresponding author.

Email addresses: ayman.karam@kaust.edu.sa (Ayman M. Karam), ahmad.alsaadi@kaust.edu.sa (Ahmad S. Alsaadi), noreddine.ghaffour@kaust.edu.sa (Noreddine Ghaffour), taousmeriem.laleg@kaust.edu.sa (Taous Meriem Laleg-Kirati)
}

then condenses on the permeate-membrane interface [1]. Since only water vapor is allowed through the hydrophobic membrane, MD has a $100 \%$ theoretical reject rate of ions.

The mass transfer driving force in MD is the partial vapor pressure difference across the membrane. Hence, unlike thermal-based conventional desalination methods, MD does not require high grade heat to vaporize the feed water, which means it can be integrated with solar thermal energy and low grade waste heat sources $[3,4]$. Also, Since MD operates at a lower hydraulic pressure, it is less susceptible to scaling and fouling, which is a general drawback of pressure-driven membrane based desalination techniques, like reverse osmosis. Moreover, the general operational concept of MD requires less demanding membrane characteristics and properties [5]. All these features make MD ideal for sustainable water desalination in remote areas [6].

To capitalize on the MD stated advantages, the MD water desalination process has to be well understood, modeled and then optimized for maximum process ef- 
ficiency. In recent years there have been some efforts to model the MD process and understand the effect of its operational parameters. The steady-state spaceindependent analysis sets the foundation for understanding the process $[7,8]$. To capture the steadystate spatial response of the process, several approaches have been proposed. In [9] energy and mass conservation laws were used to compare the energy efficiency of several MD configurations. Steady-state partial differential equation (PDE) based approaches like [10] [11], where the convection diffusion equation and the laminar steady-state Navier-Stokes equation were applied respectively, to compare experimental measurements of DCMD to simulated results. A more recent work [12], also based on energy and mass balances, compared steady-state predicted flux results to experimental measurements of a DCMD setup.

However, solar radiations or other heat sources are time varying. Therefore when coupling the MD to these sources, the inlet temperatures of the MD process are unsteady throughout the operation. Hence, due to the spatial and temporal variations of the temperatures distribution inside the MD module and other effects, it is important to learn more about the dynamic response of the process. In addition, if a failure occurs during the process operation, one can detect it by analyzing the time response of the process. All of these reasons have motivated the dynamical modeling of the MD process $[3,13,14,15,16,17,18]$. In $[3,13]$ variations of the dynamic convection equation were considered to model air gap $\mathrm{MD}$, whereas in $[14,15,16]$ the $2 \mathrm{D}$ convection diffusion equation was used to model DCMD. On the other hand, [17] proposed a black-box model based on neural-networks for the permeate gap MD setup.

There are two main limitations for most of the reported models, they are either only applicable for steady-state dimensionless analysis or computationally costly specifically for large module sizes, where a simpler modeling approaches might be required. Unlike black-box models, physical models offer more insight into the process and its operational parameters (i.e. the feed and permeate inlet temperatures and flow rates as well as the geometry of the module and the membrane properties). Alternative approaches are based on lumped-parameter models $[9,12,18]$, they offer the benefits of physical models, while maintaining a reasonable computational cost. These models are therefore suitable detailed process analysis and optimization applications. This work builds up on the more recent dynamic model proposed by Karam and Laleg [19], which is based on electrical analogy to thermal systems. In this paper, we propose to study the performance of this model in analyzing the DCMD process and showing its predictive capacity for both steady-state and time varying responses.
The proposed dynamic model accounts for the spatial and temporal simultaneous heat and mass transfer phenomena in DCMD. The water-vapor flux and the temperature distribution along the flow direction can be simulated under various conditions. By directly solving a system of differential algebraic equations (DAEs), it also offers fixable platform to carryout scale up and design studies, and enable real-time estimation of some intrinsic variables that are inaccessible in physical setups, like the temperature and vapor pressure at the membrane interfaces. Accordingly, this leads to optimal operating conditions for the MD process. Moreover, the same foundation can be easily extended to other MD configurations. We start by presenting the dynamic model for heat and mass transfer in DCMD. The response of this model is then analyzed under steadystate and time varying conditions. Finally, we present the predictive capacity of the model by carrying out several simulations and discussing the results to understand the effect of operational parameters on the heat transfer mechanism at the membrane boundary layer.

\section{Dynamic model development}

A schematic diagram of a flat-sheet DCMD module is shown in Fig.1. In this configuration, hot water is passed along a hydrophobic membrane in the feed side and cold water flows in the counter direction along the permeate side. Water vapor is driven from the feed side across the membrane and into the permeate side by the induced partial vapor pressure difference. Both heat and mass transfer processes occur simultaneously as water evaporates at the feed-membrane interface and condenses at the permeate-membrane interface. As a result, the temperature near the membrane surfaces differs from the bulk temperature of the feed and permeate streams. This is known as the temperature polarization effect. In order to quantify this effect, the temperature polarization coefficient (TPC) is defined as [20]:

$$
T P C=\frac{T_{\mathrm{mf}}-T_{\mathrm{mp}}}{T_{\mathrm{bf}}-T_{\mathrm{bp}}} .
$$

This effect reduces the mass transfer driving force, and as a result lowers the production rate of the MD process. Moreover, due to the temperature variation of the feed and permeate streams throughout the module, the water vapor flux varies along the module. Therefore, by dividing the DCMD module into small control volumes of length $d z$, we can account for the temperature changes in both the feed and permeate sides. The following subsections details more the mass and heat transfer processes.

\subsection{Mass transfer in DCMD}

The transport phenomena is described by the classic gas permeation and heat transfer theories. The mass 


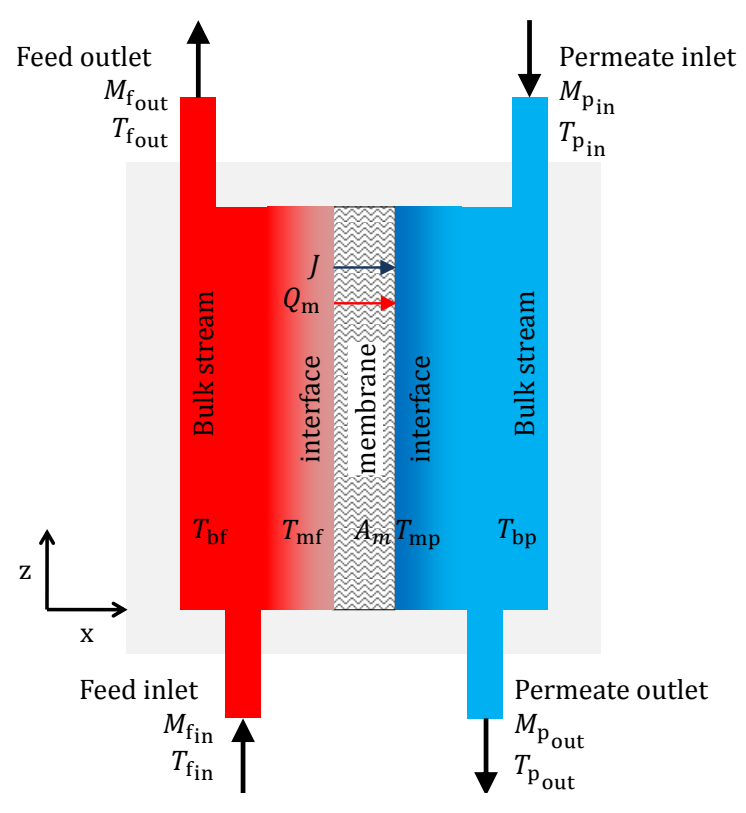

Figure 1: Schematic diagram of a DCMD module.

flux $(J)$ in DCMD is related to the saturated vapor pressure difference across the membrane $(\Delta P)$ through the membrane mass transfer coefficient $\left(B_{\mathrm{m}}\right)$, as [21]:

$$
J=B_{m} \Delta P=B_{m}\left(P_{\mathrm{mf}}-P_{\mathrm{mp}}\right) .
$$

The mechanism dominating the mass transfer through the porous membranes depends on the pore radius $(r)$ and the mean free path of the vapor molecules $(\lambda)$. For membranes with pore radius in the range of $0.5 \lambda<r<50 \lambda$, the membrane mass transfer coefficient is expressed as a parallel combination of Knudsen diffusion $\left(B_{K n}\right)$ and molecular diffusion $\left(B_{D}\right)$ coefficients [7] given by:

$$
B_{m}=\frac{1}{1 / B_{K n}+1 / B_{D}}
$$

where:

$$
B_{K n}=\frac{4}{3} \frac{\varepsilon r}{\xi \delta} \sqrt{\frac{2 m_{w}}{\pi \bar{R} T}}, B_{D}=\frac{\varepsilon}{\xi \delta} \frac{P D}{P_{a}} \frac{m_{w}}{\bar{R} T}, \quad(T \text { in } \mathrm{K}) .
$$

The saturated vapor pressure of pure water $\left(P_{w}^{s a t}[T]\right)$ as a function of temperature $\left(\right.$ in ${ }^{\circ} \mathrm{C}$ ) is given by the Antoine equation [22]:

$$
P_{w}^{s a t}[T]=\exp \left(23.1964-\frac{3816.44}{T+227.02}\right) .
$$

Dissolved salt in the feed stream reduces the saturated vapor pressure. Therefore, to compensate for this the following relation was proposed in [22]:

$$
P_{\mathrm{mf}}=\left(1-x_{\mathrm{NaCl}}\right)\left(1-0.5 x_{\mathrm{NaCl}}-10 x_{\mathrm{NaCl}}^{2}\right) P_{w}^{s a t}\left[T_{\mathrm{mf}}\right],
$$

where $x_{\mathrm{NaCl}}$ is the mole fraction of $\mathrm{NaCl}$ in the feed stream. However, the permeate is pure and the saturated vapor at the membrane-permeate interface is $P_{\mathrm{mp}}=P_{w}^{s a t}\left[T_{\mathrm{mp}}\right]$.

\subsection{Heat transfer in $D C M D$}

The following was derived in our previous work $[18,19]$ and is reproduced here for the sake of completeness and clarity. To consider spacial variations on the temperature along the feed and permeate flow directions, the DCMD module is divided into $\mathrm{N}$ controlvolume cells. Then, based on the lumped-capacitance method, a dynamical model for heat transfer is developed using the energy conservation law, where the rate of temperature change within the cell in each of the bulk feed and the bulk permeate sides is inversely proportional to the thermal capacities $C_{\mathrm{bf}}$ and $C_{\mathrm{bp}}$, respectively. Fig. 2 depicts the $\mathrm{n}^{\text {th }}$ DCMD cell, where the bulk temperatures $\left(T_{\mathrm{bf}_{\mathrm{n}}}, T_{\mathrm{bp}_{\mathrm{n}}}\right)$ are uniform throughout the cell except at the membrane interfaces due to the temperature polarization effect ${ }^{1}$. Therefore, heat transfer takes place in three stages, by conduction and due to mass transfer. In the first stage, heat is transferred from the hot bulk feed stream to the boundary layer at the feed-membrane interface, the heat transfer rate is expressed as $Q_{\mathrm{mf}}$

$$
Q_{\mathrm{mf}}=A_{m}\left(h_{\mathrm{f}}\left(T_{\mathrm{bf}_{\mathrm{n}}}-T_{\mathrm{mf}_{\mathrm{n}}}\right)+J_{\mathrm{n}} c_{p} T_{\mathrm{bf}_{\mathrm{n}}}\right) .
$$

The rate of change of the bulk feed stream energy in the $\mathrm{n}^{\text {th }}$ cell equals the rate of energy going into the cell minus the rate of energy leaving out of the cell, which is expressed as:

$$
\begin{array}{r}
C_{\mathrm{bf}} \frac{d T_{\mathrm{bf}_{\mathrm{n}}}}{d t}=Q_{\mathrm{f}_{\mathrm{n}}}-Q_{\mathrm{f}_{\mathrm{n}+1}} \\
-A_{m}\left(h_{\mathrm{f}}\left(T_{\mathrm{bf}_{\mathrm{n}}}-T_{\mathrm{mf}_{\mathrm{n}}}\right)+J_{\mathrm{n}} c_{p} T_{\mathrm{bf}_{\mathrm{n}}}\right),
\end{array}
$$

where $Q_{\mathrm{f}_{\mathrm{n}}}$ and $Q_{\mathrm{f}_{\mathrm{n}+1}}$ are the heat transfer rates into and out of the $\mathrm{n}^{\text {th }}$ feed cell, respectively.

At the second stage, heat is transferred through the membrane via three mechanisms: the first mechanism $\left(Q_{\mathrm{m} 1}\right)$ is the latent heat of vaporization $\left(H_{v}\right)$ transported by the mass flux $\left(J_{\mathrm{n}}\right)$ through the $\mathrm{n}^{\text {th }}$ cell, expressed as:

$$
Q_{\mathrm{m} 1}=A_{m} J_{\mathrm{n}} H_{v}\left[T_{\mathrm{mf}_{\mathrm{n}}}\right]=B_{m}\left(P_{\mathrm{mf}_{\mathrm{n}}}-P_{\mathrm{mp}_{\mathrm{n}}}\right) H_{v}\left[T_{\mathrm{mf}_{\mathrm{n}}}\right],
$$

where the latent heat of vaporization $H_{v}$ in $(\mathrm{KJ} / \mathrm{kg})$ is expressed as a function of temperature $\left(T\right.$ in $\left.{ }^{\circ} \mathrm{C}\right)$ :

$$
H_{v}[T]=-2.426 T+2503 .
$$

\footnotetext{
${ }^{1}$ Throughout this paper, the $\mathrm{n}^{\text {th }}$ cell is indexed by $\mathrm{n}$ as a subscript or a superscript.
} 


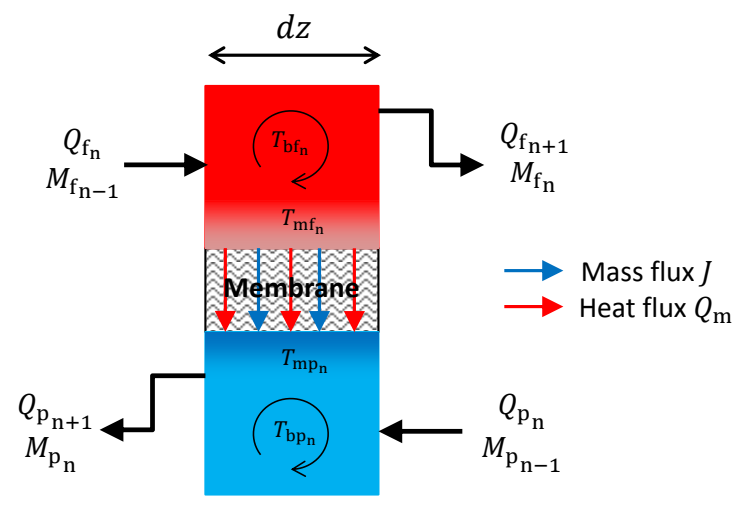

Figure 2: Schematic diagram of the $\mathrm{n}^{\text {th }}$ DCMD cell.

The second and third mechanisms are heat conduction through the membrane material and air trapped in the membrane pores which are combined in $\left(Q_{m 2}\right)$ as:

$$
Q_{\mathrm{m} 2}=A_{m} h_{\mathrm{m}}\left(T_{\mathrm{mf}}-T_{\mathrm{mp}}\right)
$$

where the membrane heat transfer coefficient $h_{\mathrm{m}}$ is the weighted average of thermal conductivity of the membrane material and air [23], $k_{m}$ and $k_{g}$ respectively, expressed as [5]:

$$
h_{\mathrm{m}}=\frac{k_{\mathrm{g}} \varepsilon+k_{\mathrm{m}}(1-\varepsilon)}{\delta} .
$$

Combining these mechanisms to write the energy balance at the membrane interfaces gives the following equation:

$$
Q_{\mathrm{mf}}=Q_{\mathrm{mp}},
$$

where the heat transfer rate at the permeate-membrane interface $\left(Q_{\mathrm{mp}}\right)$ is expressed as:

$$
\begin{aligned}
Q_{\mathrm{mp}} & =A_{m}\left(h_{\mathrm{p}}\left(T_{\mathrm{mp}_{\mathrm{n}}}-T_{\mathrm{bp}_{\mathrm{n}}}\right)+J_{\mathrm{n}} c_{p} T_{\mathrm{mp}_{\mathrm{n}}}\right) \\
& =Q_{\mathrm{m} 1}+Q_{\mathrm{m} 2} .
\end{aligned}
$$

Finally, the third stage of heat transfer where the water-vapor condenses at the permeate-membrane interface and heat is transferred to the bulk permeate mass. The rate of change of energy for the bulk permeate stream is similarly given as:

$$
\begin{array}{r}
C_{\mathrm{bp}} \frac{d T_{\mathrm{bp}_{\mathrm{n}}}}{d t}=Q_{\mathrm{p}_{\mathrm{n}}}-Q_{\mathrm{p}_{\mathrm{n}}+1} \\
+A_{m}\left(h_{\mathrm{p}}\left(T_{\mathrm{mp}_{\mathrm{n}}}-T_{\mathrm{bp}_{\mathrm{n}}}\right)+J_{\mathrm{n}} c_{p} T_{\mathrm{mp}_{\mathrm{n}}}\right),
\end{array}
$$

where $Q_{\mathrm{p}_{\mathrm{n}}}$ and $Q_{\mathrm{p}_{\mathrm{n}+1}}$ are also the heat transfer rate into and out of the $\mathrm{n}^{\text {th }}$ permeate cell, respectively.

The two heat transfer coefficients at the membrane interfaces $\left(h_{\mathrm{f}}, h_{\mathrm{p}}\right)$ can be calculated from empirical correlations. These correlations depend on the flow characteristic (laminar or turbulent) and vary accordingly.
In this study, the following relation is used for both heat transfer coefficients [7]:

$$
h=0.13 \operatorname{Re}^{0.64} \operatorname{Pr}^{1 / 3} \frac{k_{\mathrm{w}}}{D_{h}},
$$

where $R e$ and $\operatorname{Pr}$ are the Reynolds and Prandtl numbers, respectively.

The analysis done so far has not quantified the coupling terms between neighboring cells i.e. $\left(Q_{\mathrm{f}_{\mathrm{n}}}, Q_{\mathrm{f}_{\mathrm{n}+1}}\right.$, $Q_{\mathrm{p}_{\mathrm{n}}}$, and $Q_{\mathrm{p}_{\mathrm{n}+1}}$ ). Equations (7)-(13) can be represented by an electrical analogue circuit. This representation has a significant advantage, it allows to couple neighboring cells by modeling the thermal inertia of the system, as discussed in the next subsection.

\subsection{Dynamic model formulation}

The dynamical model is based on electrical analogy to thermal systems, which can be derived from the basic laws of each system. Appendix A details the derivation process and a summery of the analogy is shown in Table A.3. Indeed electrical-analogy based methods have been used to describe the dynamical behavior of many industrial and biological systems such as heat exchangers [24], and the human cardiovascular system [25]. Moreover, it was shown that the transient diffusion phenomena and the heat transfer due to nonsteady fluid flow can be described by an electrical analogue, see [26] and [27], respectively. Literature above motivated the method presented in this paper.

Based on the equations derived for the $\mathrm{n}^{\text {th }}$ DCMD cell, an electrical analogue is constructed to derive the heat and mass transfer equations for the coupled neighboring cells. The electrical analogue of the $\mathrm{n}^{\text {th }}$ cell of the DCMD module is shown in Fig. 3. The thermal capacity of the feed and permeate bulk sides is represented by $\mathrm{C}_{\mathrm{bf}}$ and $\mathrm{C}_{\mathrm{bp}}$, respectively. In each of the three stages of heat transfer discussed in Section 2.2, the heat transfer rate by conduction is proportional to the temperature difference across the thermal resistances $R_{f}, R_{m}$, and $R_{p}$, whereas the heat transfer rate due to mass transfer is modeled by the current sources $Q_{1}^{\mathrm{n}}, Q_{\mathrm{m} 1}^{\mathrm{n}}$, and $Q_{2}^{\mathrm{n}}$. This completes the analogy of heat transfer within the same cell, and in order to couple neighboring cells, the series impedances (opposition to the heat transfer rate) $\mathrm{Z}_{\mathrm{f}}^{\mathrm{n}}$ and $\mathrm{Z}_{\mathrm{p}}^{\mathrm{n}}$ are introduced. Apart from the series impedances, Table 1 details the expression of each element in the electrical analogue circuit.

Another important part of DCMD electrical analogy is to consider the heat transfer by the feed and permeate inlet mass flow rates. Therefore, the electrical analog network should be fed and terminated properly to account for the heat transfer rates into and out of the MD module. This, as well as the series impedances, are fully discussed in Appendix B, and the final results are presented as follows. The temperature drop from 


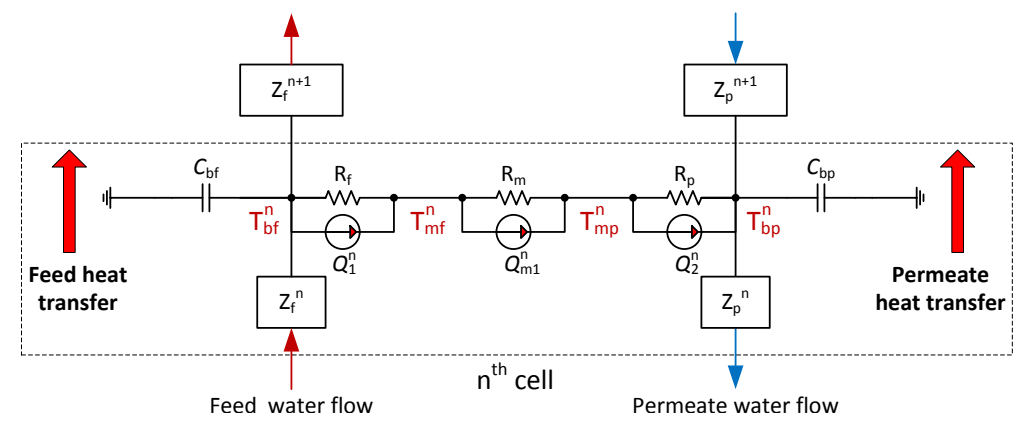

Figure 3: Electrical analogue of the $\mathrm{n}^{\text {th }}$ cell of the DCMD module.

Table 1: Elements of the electrical thermal network for DCMD cell

\begin{tabular}{l|l|c}
\hline Element & Expression & Unit \\
\hline $\mathrm{R}_{\mathrm{f}}$ & $\frac{1}{A_{m} h_{\mathrm{f}}}$ & ${ }^{\circ} \mathrm{C} / \mathrm{W}$ \\
$\mathrm{R}_{\mathrm{m}}$ & $\frac{1}{A_{m} h_{\mathrm{m}}}$ & ${ }^{\circ} \mathrm{C} / \mathrm{W}$ \\
$\mathrm{R}_{\mathrm{p}}$ & $\frac{1}{A_{m} h_{\mathrm{p}}}$ & ${ }^{\circ} \mathrm{C} / \mathrm{W}$ \\
$Q_{1}^{\mathrm{n}}$ & $A_{m} J_{\mathrm{n}} c_{p} T_{\mathrm{bf}}$ & $\mathrm{W}$ \\
$Q_{\mathrm{m} 1}^{\mathrm{n}}$ & $A_{m} J_{\mathrm{n}} H_{v}\left[T_{\mathrm{mf}}\right]$ & $\mathrm{W}$ \\
$Q_{\mathrm{mp}}^{\mathrm{n}}$ & $A_{m} J_{\mathrm{n}} c_{p} T_{\mathrm{mp}}$ & $\mathrm{W}$ \\
$C_{\mathrm{bf}}$ & $\rho_{\mathrm{w}} c_{p} v_{\mathrm{bf}}$ & $\mathrm{J} /{ }^{\circ} \mathrm{C}$ \\
$C_{\mathrm{bp}}$ & $\rho_{\mathrm{w}} c_{p} v_{\mathrm{bp}}$ & $\mathrm{J} /{ }^{\circ} \mathrm{C}$ \\
\hline
\end{tabular}

one cell to the next in the feed side is proportional to the series impedance $\mathrm{Z}_{\mathrm{f}}^{\mathrm{n}}$, which is given as:

$$
\mathrm{Z}_{\mathrm{f}}^{\mathrm{n}}=\mathrm{R}_{\mathrm{fz}}^{\mathrm{n}}+j \omega \mathrm{L}_{\mathrm{f}}^{\mathrm{n}}
$$

where:

$$
\begin{aligned}
\mathrm{R}_{\mathrm{fz}}^{\mathrm{n}} & =\frac{1}{M_{\mathrm{f}_{\mathrm{n}}}^{2} c_{p}^{2}\left(\mathrm{R}_{\mathrm{f}}+\mathrm{R}_{\mathrm{m}}+\mathrm{R}_{\mathrm{p}}\right)}, \\
\mathrm{L}_{\mathrm{f}}^{\mathrm{n}} & =\frac{\mathrm{R}_{\mathrm{fz}}^{2} C_{\mathrm{bf}}}{4} .
\end{aligned}
$$

The symbol $j \omega$ is used to indicate complex impedance. In this case the thermal inertia of the $\mathrm{n}^{\text {th }}$ cell feed side is modeled by the inductor $\mathrm{L}_{\mathrm{f}}^{\mathrm{n}}$, which accounts for the dynamic response that resist sudden changes to temperature by changing the inlet mass flow rate. On the other hand, the steady-state response is given by the thermal resistance $R_{\mathrm{fz}}^{\mathrm{n}}$. Similarly, the permeate side series impedance $\left(\mathrm{Z}_{\mathrm{p}}^{\mathrm{n}}\right)$ is given as:

$$
\mathrm{Z}_{\mathrm{p}}^{\mathrm{n}}=\mathrm{R}_{\mathrm{pz}}^{\mathrm{n}}+j \omega \mathrm{L}_{\mathrm{p}}^{\mathrm{n}}
$$

where:

$$
\begin{aligned}
& \mathrm{R}_{\mathrm{pz}}^{\mathrm{n}}=\frac{1}{M_{\mathrm{p}_{\mathrm{n}}}^{2} c_{p}^{2}\left(\mathrm{R}_{\mathrm{f}}+0.5 \mathrm{R}_{\mathrm{m}}+\mathrm{R}_{\mathrm{p}}\right)}, \\
& \mathrm{L}_{\mathrm{p}}^{\mathrm{n}}=\frac{\mathrm{R}_{\mathrm{pz}}^{2} C_{\mathrm{bp}}}{4} .
\end{aligned}
$$

Both of $\mathrm{Z}_{\mathrm{f}}^{\mathrm{n}}$ and $\mathrm{Z}_{\mathrm{p}}^{\mathrm{n}}$ parametrization was done based on experimental identification using real data.

The other point is about considering the heat transfer rates into and out of the MD module. The feed and permeate inlet temperatures are simulated by voltage sources that can be set as required. This allows to simulate any desired inlet temperature profile. On the other hand, by conservation of energy, the feed outlet temperature cannot go below the permeate inlet temperature and vice versa, the permeate outlet temperature can not exceed the feed inlet temperature. Based on this argument, the feed and permeate outlet sides are terminated across a termination resistances $\left(R_{f_{\text {term }}}\right.$ and $\mathrm{R}_{\mathrm{f}_{\text {term }}}$, receptively) as:

$$
\begin{aligned}
& 0=T_{\mathrm{f}_{\text {out }}}-T_{\mathrm{p}_{\text {in }}}-R_{\mathrm{f}_{\text {term }}} Q_{\mathrm{f}_{\mathrm{N}+1}}, \\
& 0=T_{\mathrm{p}_{\text {out }}}-T_{\mathrm{f}_{\mathrm{in}}}+R_{\mathrm{p}_{\text {term }}} Q_{\mathrm{p}_{1}} .
\end{aligned}
$$

The elements of the electrical analogue network are now properly identified and parameterized, and the complete network is shown in Fig.4. Based on this analogue circuit, electrical laws are applied to derive the model of DCMD.

The coupling between neighboring cells can now be quantified by the current (in thermal analogy, current is the heat transfer rate) through the inductors. At the feed side, the rate of change of the heat transfer rate from the $n-1$ cell to the $n^{\text {th }}$ cell is proportional to the temperature difference between them. Taking into consideration the series impedance $\mathrm{Z}_{\mathrm{n}}^{\mathrm{f}}$, this is expressed as:

$$
\frac{d Q_{\mathrm{f}_{\mathrm{n}}}}{d t}=\frac{1}{\mathrm{~L}_{\mathrm{f}}^{\mathrm{n}}} T_{\mathrm{bf}_{\mathrm{n}-1}}-\frac{\mathrm{R}_{\mathrm{fz}}^{\mathrm{n}}}{\mathrm{L}_{\mathrm{f}}^{\mathrm{n}}} Q_{\mathrm{f}_{\mathrm{n}}}-\frac{1}{\mathrm{~L}_{\mathrm{f}}^{\mathrm{n}}} T_{\mathrm{bf}_{\mathrm{n}}} .
$$

Using Kirchoff's current law at the $\mathrm{n}^{\text {th }}$ feed node, it follows that the rate of change for the bulk feed temperature $\left(T_{\mathrm{bf}_{\mathrm{n}}}\right)$ is:

$$
\begin{aligned}
\frac{d T_{\mathrm{bf}_{\mathrm{n}}}}{d t}= & \frac{1}{C_{\mathrm{bf}}} Q_{\mathrm{f}_{\mathrm{n}}}-\frac{1}{C_{\mathrm{bf}}}\left(\frac{1}{\mathrm{R}_{\mathrm{f}}}+J_{\mathrm{n}} A_{m} c_{p}\right) T_{\mathrm{bf}_{\mathrm{n}}} \\
& -\frac{1}{C_{\mathrm{bf}}} Q_{\mathrm{f}_{\mathrm{n}+1}}+\frac{1}{C_{\mathrm{bf}} \mathrm{R}_{\mathrm{f}}} T_{\mathrm{mf}_{\mathrm{n}}} .
\end{aligned}
$$




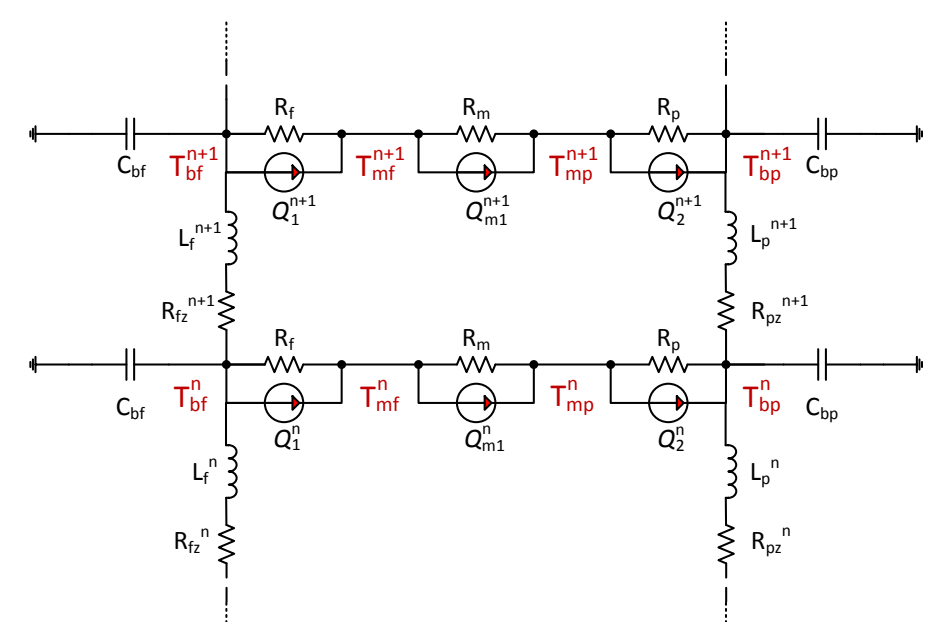

Figure 4: Completed electrical analogue of the DCMD module. This figure shows two cells and a similar structure will build the whole system

Notice that Eq.(24) is equivalent to Eq.(7), but now Eq.(23) describes the dynamics of the heat transfer rates into and out of the $\mathrm{n}^{\text {th }}$ feed cell $\left(Q_{\mathrm{f}_{\mathrm{n}}}\right.$ and $Q_{\mathrm{f}_{\mathrm{n}+1}}$, respectively).

Similarly for the permeate side, the rate of change of the heat transfer rate $\left(Q_{\mathrm{p}_{\mathrm{n}}}\right)$ is

$$
\frac{d Q_{\mathrm{p}_{\mathrm{n}}}}{d t}=\frac{1}{\mathrm{~L}_{\mathrm{p}}^{\mathrm{n}}} T_{\mathrm{bp}_{\mathrm{n}-1}}-\frac{\mathrm{R}_{\mathrm{pz}}^{\mathrm{n}}}{\mathrm{L}_{\mathrm{p}}^{\mathrm{n}}} Q_{\mathrm{p}_{\mathrm{n}}}-\frac{1}{\mathrm{~L}_{\mathrm{p}}^{\mathrm{n}}} T_{\mathrm{bp}_{\mathrm{n}}},
$$

and the dynamics of the bulk permeate temperature $\left(T_{\mathrm{bp}_{\mathrm{n}}}\right)$ is:

$$
\begin{aligned}
\frac{d T_{\mathrm{bp}_{\mathrm{n}}}}{d t}= & \frac{1}{C_{\mathrm{bp}}} Q_{\mathrm{p}_{\mathrm{n}}}-\frac{1}{C_{\mathrm{bp}} \mathrm{R}_{\mathrm{p}}} T_{\mathrm{bp}_{\mathrm{n}}}-\frac{1}{C_{\mathrm{bp}}} Q_{\mathrm{p}_{\mathrm{n}}+1} \\
& +\frac{1}{C_{\mathrm{bp}}}\left(\frac{1}{\mathrm{R}_{\mathrm{p}}}+J_{\mathrm{n}} A_{m} c_{p}\right) T_{\mathrm{mp}_{\mathrm{n}}} .
\end{aligned}
$$

The coupling between the feed and the permeate dynamics in the $\mathrm{n}^{\text {th }}$ cell is established through the algebraic constraints (11) and (12), which are written in residue form as:

$$
\begin{aligned}
0 & =\left(\frac{1}{\mathrm{R}_{\mathrm{f}}}+J_{\mathrm{n}} A_{m} c_{p}\right) T_{\mathrm{bf}_{\mathrm{n}}}-\frac{1}{\mathrm{R}_{\mathrm{f}}} T_{\mathrm{mf}_{\mathrm{n}}} \\
& -\left(\frac{1}{\mathrm{R}_{\mathrm{p}}}+J_{\mathrm{n}} A_{m} c_{p}\right) T_{\mathrm{mp}_{\mathrm{n}}}+\frac{1}{\mathrm{R}_{\mathrm{p}}} T_{\mathrm{bp}_{\mathrm{n}}} \\
0 & =\left(\frac{1}{\mathrm{R}_{\mathrm{m}}}+\frac{1}{\mathrm{R}_{\mathrm{p}}}+J_{\mathrm{n}} A_{m} c_{p}\right) T_{\mathrm{mp}_{\mathrm{n}}}-\frac{1}{\mathrm{R}_{\mathrm{p}}} T_{\mathrm{bp}_{\mathrm{n}}} \\
& -J_{\mathrm{n}} A_{m} H_{v}\left[T_{\mathrm{mf}_{\mathrm{n}}}\right]-\frac{1}{\mathrm{R}_{\mathrm{m}}} T_{\mathrm{mf}_{\mathrm{n}}}
\end{aligned}
$$

The outlet temperatures at the terminal cells of the feed and permeate analogue are also given by the algebraic equations (21) and (22). Full details on this model can be found at [19].
The proposed model is now completed with all elements of the network analyzed and parameterized. In this model, the temperatures in each cell and the heat transfer rates into and out of the cell are computed. The manipulated variables are the inlet feed and permeate temperatures and flow rates; the outputs are the water vapor flux in each cell, which when averaged together represent the overall flux of the DCMD module, and the feed and permeate outlet temperatures.

\subsection{MATLAB implementation}

This model was implemented using MATLAB [30] environment, which allows the user to easily adjust the model to simulate various experimental setups and conditions and accurately predict the steady-state and time varying behaviors of the DCMD process. In addition, the same model enables scale up simulations which facilitate module design and process optimization. By increasing the number of total cells $(\mathrm{N})$, the desired level of performance can be achieved. For all simulations in this work, a total of 10 cells were used to simulate the DCMD flat-sheet setup detailed in the previous section and the model was solved using MATLAB ode15s solver which gave accurate and fast results.

\section{Experimental setup and materials}

The DCMD lab scale setup used in this experimental work was locally designed and fabricated at KAUST [28]. A schematic diagram of the setup is presented in Figure 5. All experimental runs were conducted in a $0.1 \mathrm{~m} \times 0.05 \mathrm{~m} \times 0.002 \mathrm{~m}$ flat sheet membrane module made of Poly Methyl Methacrylate (PMMA) material. A composite membrane with a poly tetra fluoroethylene (PTFE) active layer and a non-woven poly propylene 


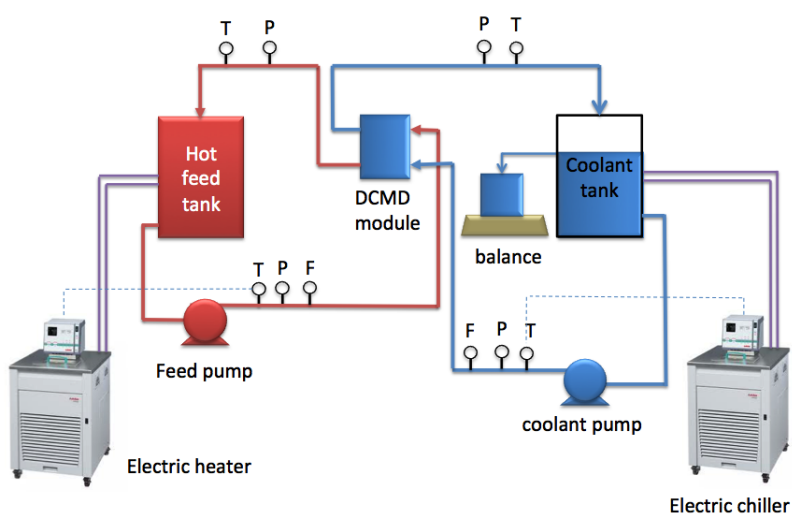

Figure 5: A schematic diagram of the experimental lab scale setup.

Table 2: DCMD Module Parameters

\begin{tabular}{l|c}
\hline Property & Value \\
\hline Membrane material & PTFE \\
Active area & $0.005 \mathrm{~m}^{2}$ \\
Total thickness & $0.170 \mathrm{~mm}$ \\
Pore size & $0.27 \mu \mathrm{m}$ \\
Porosity & $77 \%$ \\
Liquid Entry Pressure & $15 \mathrm{psi}$ \\
First bubble point & $0.42 \mu \mathrm{m}$ \\
Contact angle & $140 \pm 3^{\circ}$ \\
\hline
\end{tabular}

support layer was used in all experiments. Details of the membrane characteristics and its performance for seawater desalination were widely reported in previous works, e.g. $[2,28,29]$. Some of these parameters are presented in Table 2 .

For the steady-state experiments, Red Sea water was preheated to the desired temperature and circulated through the feed side of the membrane, while deionized (DI) water was circulated through the other side of the membrane simultaneously in a counter-current mode. The inlet feed and coolant temperatures were controlled using thermo-regulators. Four experiments were carried out, at various feed inlet temperatures $\left(40^{\circ} \mathrm{C}, 50^{\circ} \mathrm{C}, 60^{\circ} \mathrm{C}\right.$, and $\left.70^{\circ} \mathrm{C}\right)$. Fresh seawater was used for each experiment.

For the time varying response experiment, the influence of feed water temperature ranging from $30^{\circ} \mathrm{C}$ to $68^{\circ} \mathrm{C}$ on trans-membrane flux was also studied by ramping the feed inlet temperature at a rate of $0.05^{\circ} \mathrm{C}$ per minute. During ramping experiment, the coolant temperature was also maintained at $20^{\circ} \mathrm{C}$.

For all experiments, the feed and coolant flow rates were kept constant at 90 liter/hr and 60 liter/hr, respectively. The inlet and outlet temperatures of the feed and coolant side were measured by thermocouple sensors with an accuracy of $\pm 1.0^{\circ} \mathrm{C}$. The watervapor flux produced by the DCMD process increases

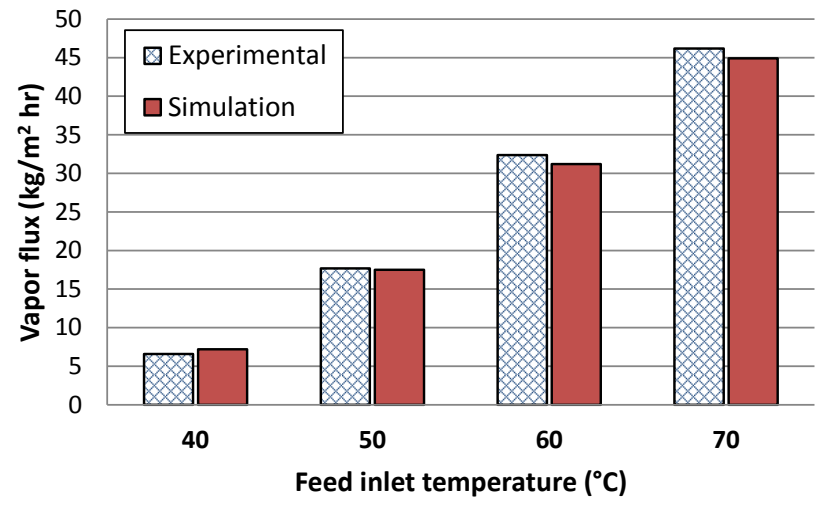

Figure 6: Steady-state vapor flux at different feed inlet temperatures.

the volume of water in the coolant tank and, as a result, overflow occurs through an outlet of the coolant tank. To measure the water-vapor flux, the overflow was collected in a separate container placed on a weighing balance (Mattler Toledo NewClassic ML 3200g) with an accuracy of $0.02 \mathrm{~g}$. The increase in weight of the container was continuously monitored and recorded. All measurements were fed through a data acquisition unit into an NI LabView software. The conductivity of the coolant and feed solutions was continuously monitored and measured using conductivity meters (Oakton Eutech Instruments, Malaysia) with multiple ranges (0 to 20.00, 20.00 to $200.0,200.0$ to $2000 \mathrm{microS} / \mathrm{cm}$; 0 to $20.00,20.200 .0 \mathrm{mS} / \mathrm{cm}$ ) and an accuracy of $\pm 1 \%$ of the full scale.

\section{Validation results and discussion}

To validate the proposed model, experimental data was collected for both steady-state and time-varying system responses. The effect of the feed inlet temperature was investigated and the results are presented and discussed in the following subsections.

\subsection{Steady-state validation at various feed inlet tem- peratures}

One of the main factors that significantly effect the vapor mass flux in DCMD is the feed inlet temperature. Therefore, it is important to demonstrate that the proposed model is adequate to predict the steady state flux at different feed inlet temperatures. The permeate inlet temperature was maintained at $20^{\circ} \mathrm{C}$ while the feed inlet temperature was increased from $40^{\circ} \mathrm{C}$ to $70^{\circ} \mathrm{C}$ in steps of $10^{\circ} \mathrm{C}$. The simulation results presented in Fig. 6 shows a very good agreement with the experimental data throughout the wide range of feed inlet temperatures. The maximum absolute error is $1.3 \mathrm{~kg} / \mathrm{m}^{2} \mathrm{hr}$ at $70^{\circ} \mathrm{C}$, while an error of less than $1.0 \mathrm{~kg} / \mathrm{m}^{2} \mathrm{hr}$ was observed for the other temperatures. 


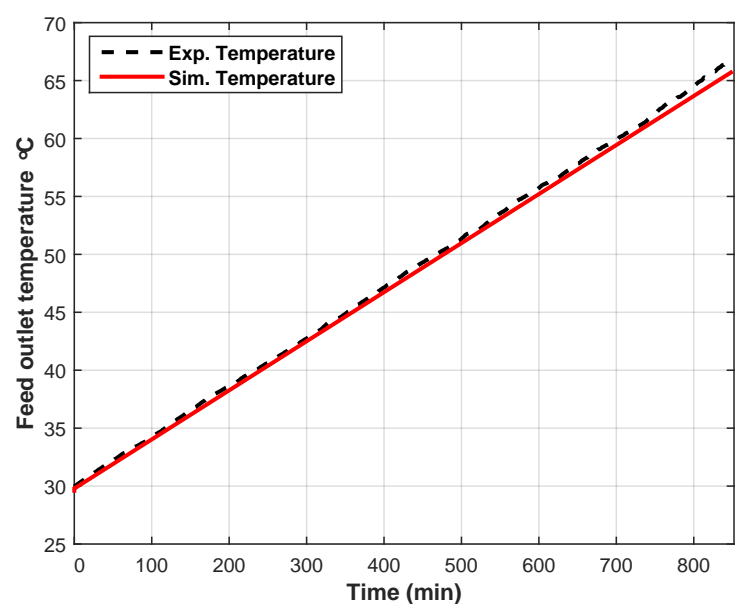

Figure 7: Feed outlet temperature for a ramp feed inlet temperature from $30^{\circ} \mathrm{C}$ to $68^{\circ} \mathrm{C}$.

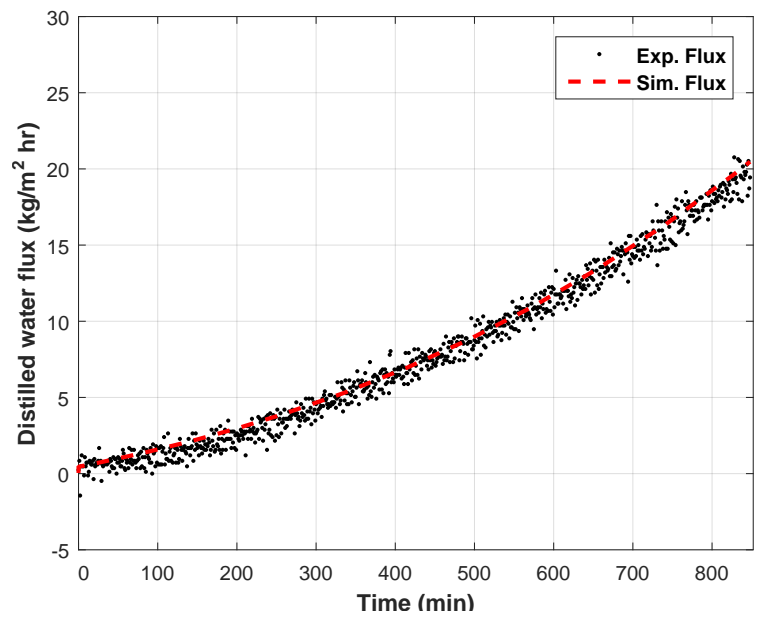

Figure 8: Vapor flux for a ramp feed inlet temperature from $30^{\circ} \mathrm{C}$ to $68^{\circ} \mathrm{C}$.

\subsection{Dynamic response of the system}

To study the time varying response of the DCMD process, an experiment was designed to ramp up the feed inlet temperature from $30^{\circ} \mathrm{C}$ to $68^{\circ} \mathrm{C}$ with an increment of $0.1^{\circ} \mathrm{C}$ per two minutes approximately, while maintaining the permeate inlet temperature constant at $20^{\circ} \mathrm{C}$. Measurements of the feed outlet temperature and water vapor flux were recorded once every minute during the course of approximately 14 hours experiment. Using the same model parameters as in the steady-state simulations, the response of the system was simulated. Fig. 13 depicts the simulated (solid line) and the experimental measurements (dashed-line) of the feed outlet temperature. We can see that the feed outlet temperature linearly follows the inlet profile and it is clear that the simulation results closely match the experimental data. The simulation results of distilled water flux are shown in Fig. 8. Since the vapor flux is a nonlinear function of the trans-membrane tem-

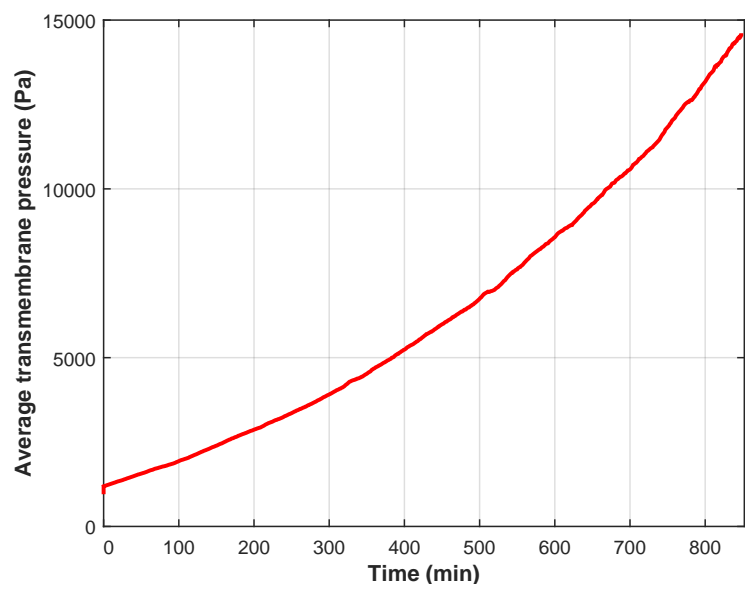

Figure 9: Average pressure differential across the membrane predicted over time for a ramp feed inlet temperature from $30^{\circ} \mathrm{C}$ to $68^{\circ} \mathrm{C}$. This shows an exponential relationship between the feed inlet temperature and pressure differential.

perature difference, we noticed an exponential increase in the flux with respect to the feed inlet temperature. Also, the figure shows a good agreement between the measured and simulated flux.

Based on the satisfactory results obtained for both the steady-state and time varying response validations, the same model can be used to solve for intrinsic variables that are not accessible in the physical setup. For instance, in the time varying ramp experiment, the average pressure differential grows exponentially with respect to the linear increase in the feed inlet temperature, see Fig.9.

\subsection{Maximizing the DCMD process efficiency}

We would like to apply the proposed model to investigate the DCMD process and optimize its efficiency. Specifically, we want to find the optimal inlet mass flow rates of the feed and permeate streams that maximizes the process efficiency for any given module size. Define the thermal conversion efficiency as the ratio between the production rate in $\mathrm{kg} / \mathrm{hr}$ and the supplied thermal energy calculated as $Q_{\mathrm{in}}=M_{\mathrm{f}_{\mathrm{in}}} c_{p} T_{\mathrm{f}_{\mathrm{in}}}$. The water vapor flux and production rate $(\mathrm{kg} / \mathrm{hr})$ are simulated under different feed and permeate inlet velocities, $0.2,0.4,0.6$, and $0.8 \mathrm{~m} / \mathrm{s}$, while the feed and permeate inlet temperatures were kept at $60^{\circ} \mathrm{C}$ and $60^{\circ} \mathrm{C}$, respectively. The residence time (restime) of the feed and permeate streams is increased by increasing the module length according to this relationship, $r e s_{\text {time }}=$ inlet velocity/module length, while the module width is set to $0.4 \mathrm{~m}$. In this simulation, we notice that as the length of the module increases the average flux decreases, as shown in Fig. 10. This is due to the following reasons:

1. As the residence time increases, more heat is lost by conduction through the membrane. 


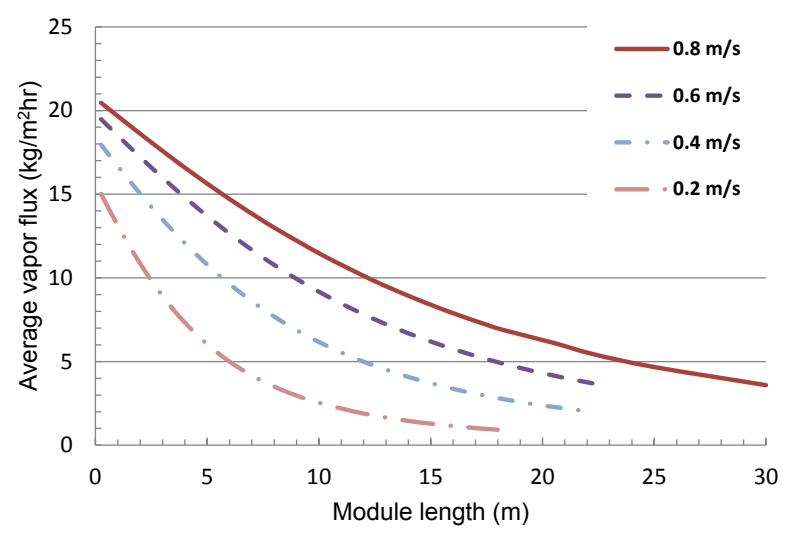

Figure 10: Predicted flux vs length for velocities $0.8,0.6,0.4,0.2$ $\mathrm{m} / \mathrm{s}$, top to bottom respectively

2. The non-linearity of the relationship between the saturation vapor pressure and temperature. The exponential relationship between the temperature and pressure is the key factor here. Here are two cases that demonstrate this point.

Case 1: the temperature at the feed membrane interface is $50^{\circ} \mathrm{C}$ and at the permeate membrane side is $40^{\circ} \mathrm{C}$. Calculating the pressure difference across the membrane gives $P_{1}=4970 \mathrm{~Pa}$.

Case 2: the temperature at the feed membrane interface is $60^{\circ} \mathrm{C}$ and at the permeate membrane side is $50^{\circ} \mathrm{C}$. Calculating the pressure difference across the membrane gives $P_{2}=18847 \mathrm{~Pa}$.

In both cases a temperature difference across the membrane of $10^{\circ} \mathrm{C}$, but the flux generated in case 2 is much higher. As the DCMD module length increases, the temperature drop in the feed side from inlet to outlet increases. Whereas for the permeate side, as the length is increased, the temperature rise from inlet to outlet increases. At some point the pressure differential along the module length decrease, which results in lower average flux.
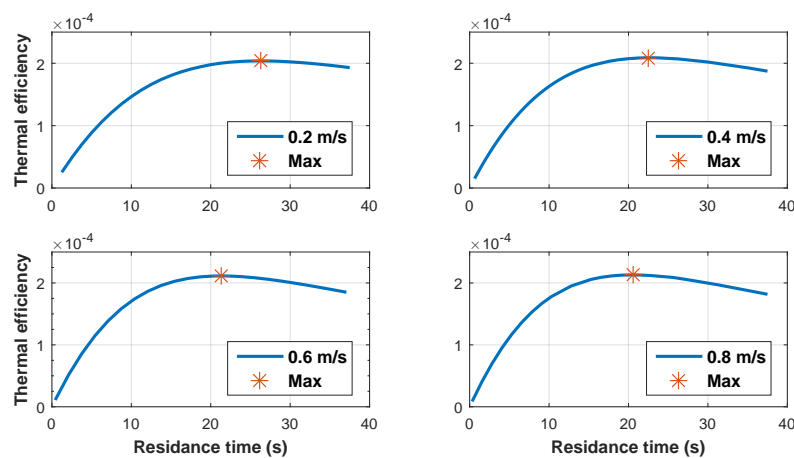

Figure 11: Thermal conversion efficiency $(\mathrm{kg} / \mathrm{hr} \mathrm{W})$ for velocities $0.2,0.4,0.6,0.8 \mathrm{~m} / \mathrm{s}$. Maximum efficiency is marked with a star for each plot.

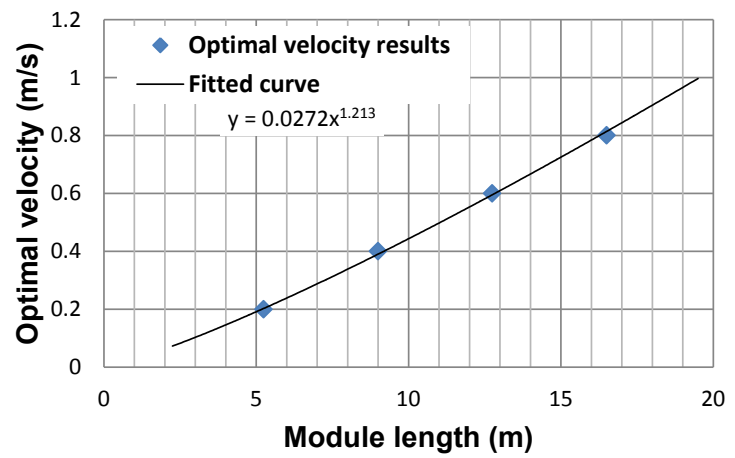

Figure 12: Optimal residence time vs optimal length. Notice that if the module length increases, then the feed and permeate inlet velocities should be high as well.

On the other hand, the thermal conversion efficiency increases rapidly as the residence time increases until it reaches a maximum value after which it starts to gradually decline, as seen in Fig. 11. An important remark regarding the optimal residence time of water inside the DCMD module channels is observed. For small lengths, it is optimal to run at relatively slow velocities and vice versa, as shown in Fig.12. Therefore, there exist an optimal inlet velocity for each module length, which achieves maximum efficiency. Plotting the optimal velocity vs the module length, the following relation can be obtained by fitting the points to a curve, $v=0.0272 x^{1.213}$.

\subsection{Step responses of the DCMD process}

An other important advantage of the proposed model is the ability to obtain the time response under dynamic changes in the DCMD process. In this simulation, the feed and permeate inlet velocities are kept constant at $0.4 \mathrm{~m} / \mathrm{s}$, the permeate inlet temperature is set to $20^{\circ} \mathrm{C}$, while the feed inlet temperature is stepped from $50^{\circ} \mathrm{C}$ to $60^{\circ} \mathrm{C}$ at time $\mathrm{t}=15 \mathrm{~s}$. The time response of the feedbulk temperature distribution over the module length is depicted in Fig. 13, where each curve shows the temperature distribution at a given time instant. Starting from the lowest blue curve at $\mathrm{t}=15 \mathrm{~s}$, the module takes $12.5 \mathrm{~s}$ in response time to reach the upper red curve which shows the new steady state temperature distribution. Fig. 14 shows the step response of the bulkfeed and membrane-feed interface temperatures at the cell corresponding to $1.75 \mathrm{~m}$ from the feed inlet. Notice that the DCMD process response is relatively fast, given sufficient actuation power. The flux response is presented in Fig. 15, it also takes about 12 seconds to reach the new steady-state value.

\subsection{Temperature prediction along the module length}

Predicting the temperature at the membrane boundary layers is essential to accurately quantify the wa- 


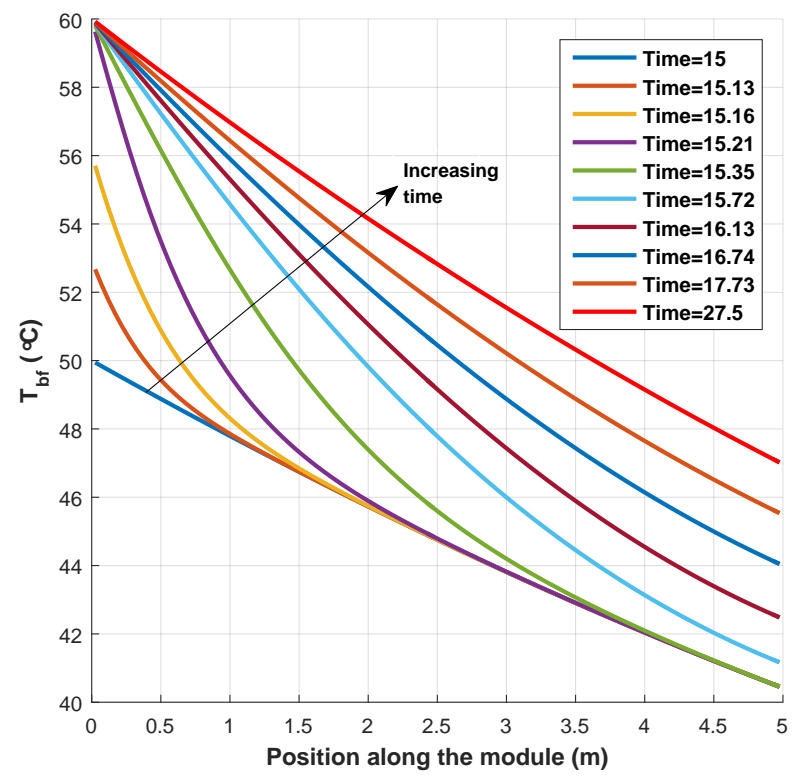

Figure 13: The time response of the bulk feed temperature distribution for a step change of the feed inlet temperature from $50^{\circ} \mathrm{C}$ to $60^{\circ} \mathrm{C}$, where each curve shows the response at a given time instant.
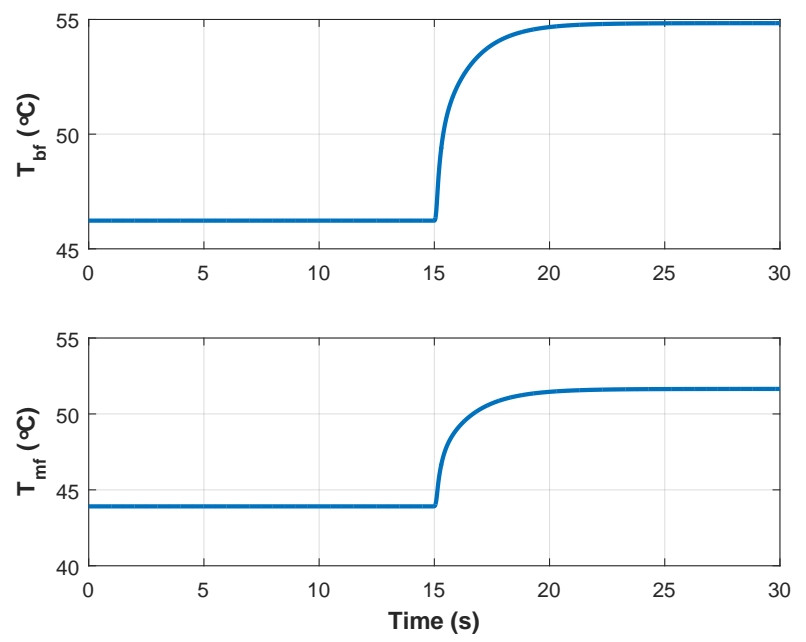

Figure 14: The time response for a step change in the feed inlet temperature of the bulk feed (top) and membrane-feed (bottom) temperatures at the cell corresponding to $1.75 \mathrm{~m}$ from the feed inlet.

ter vapor flux. This model provides distributed temperature predictions along the length of the module. Fig. 16 shows the feed and permeate bulk and boundary layers temperatures under the conditions: module length of $16.5 \mathrm{~m}$, width of $0.4 \mathrm{~m}$, feed and permeate inlet temperatures of $60^{\circ} \mathrm{C}$ and $20^{\circ} \mathrm{C}$, respectively, and the linear velocities of both sides was $0.4 \mathrm{~m} / \mathrm{s}$. Since this is a counter-current flow setup, the bulk feed and feed-membrane boundary temperatures drop with the flow direction, whereas the bulk permeate and bound-

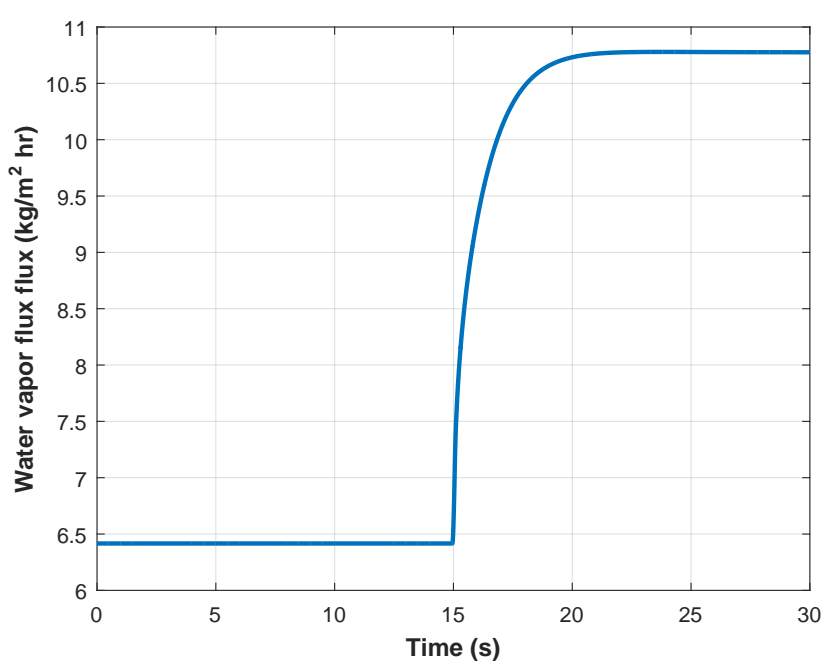

Figure 15: Water-vapor flux response for a step change in the feed inlet temperature.

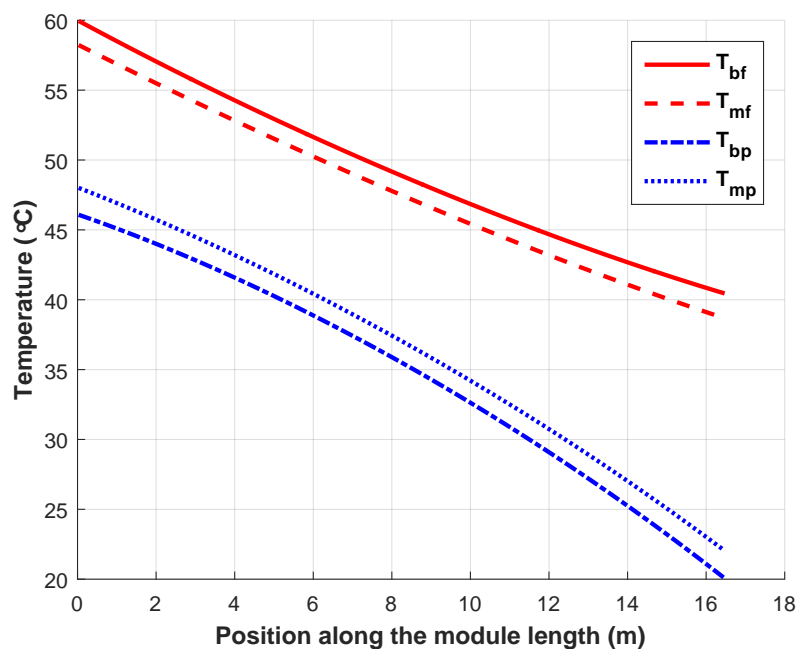

Figure 16: Predicted temperature distribution along the length of the module for both the feed and permeate sides.

ary layer temperature increase with the flow direction. This figure clearly shows the nonlinear temperature distribution along the module length.

\subsection{Effect of linear velocity on the TPC}

To investigate the effect of feed/permeate inlet velocities on the TPC, we design the following simulation. The feed and permeate inlet temperatures are kept constant at $60^{\circ} \mathrm{C}$ and $20^{\circ} \mathrm{C}$, respectively, while the inlet velocities were increased from $0.1 \mathrm{~m} / \mathrm{s}$ to $0.65 \mathrm{~m} / \mathrm{s}$. Fig. 17 shows the TPC as a function of the inlet velocities. It is clear that increasing the inlet velocity has a desirable effect on the the TPC. However, this effect begins to saturate starting from $0.5 \mathrm{~m} / \mathrm{s}$ onwards. As the velocity inside the feed/permeate channels increases, the 


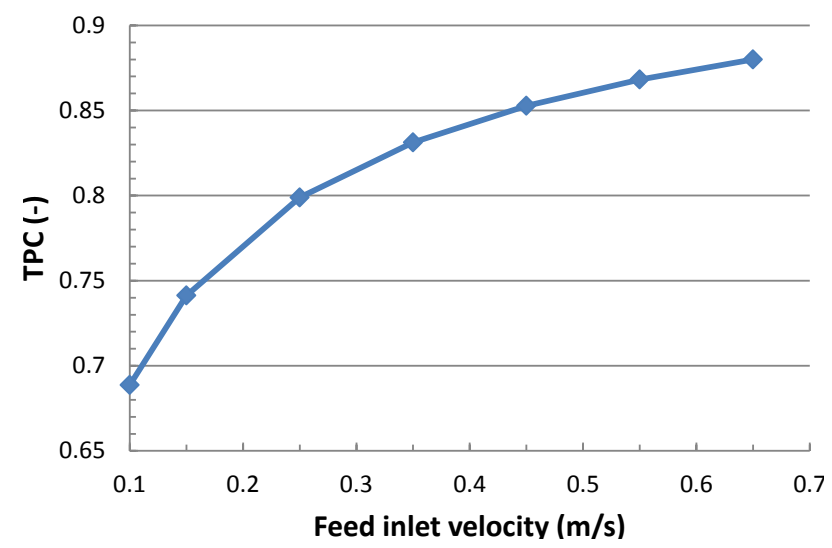

Figure 17: TPC as a function of feed inlet velocity.

flow becomes more energetic and, as a result, the thermal boundary layer thickness is reduced. Therefore the temperatures at the membrane interfaces are brought closer towards that of the respective bulk temperature.

\section{Conclusions}

This paper presented the steady-state and dynamic responses of a lumped-parameter dynamic model for DCMD. The model was derived from an electrical thermal network equivalent to the DCMD process. Experimental flux measurements under various feed inlet temperatures were recorded and compared with simulated results to validate the steady-state model behavior. The dynamic response to a feed inlet temperature ramp up experiment was validated for both the water vapor flux and feed outlet temperature. The permeate flux increased with increasing temperature and the simulated steady-state and dynamic results showed great agreement with experimental measurements.

We investigated the optimal inlet velocity of the feed and permeate streams for maximum process efficiency. This is useful for both module design and for optimal operation of existing modules. The dynamic response of the system to a step change in feed inlet temperature was investigated. It was found that the bulk-feed temperature increased gradually from inlet to outlet. The water vapor flux response reaches its new steady-state value relatively fast from the onset of the step input. The temperature distribution profiles along the length of the module were predicted at the feed and permeate bulk and boundary layers interfaces and found to be nonlinear. Obtaining the distributed temperature profiles enables to characterize the TPC under various feed and permeate inlet velocities. It was shown that TPC increases with higher velocities, reaching a maximum value of 0.88 at inlet velocities of $0.65 \mathrm{~m} / \mathrm{s}$, with asymptotic behavior at high velocities. Throughout, we have demonstrated the accuracy and applicability of the proposed model for DCMD process prediction, efficiency optimization, and analysis.

\section{Nomenclature}

$A_{c s}$ Cross sectional area $\left(\mathrm{m}^{2}\right)$

$A_{m}$ Differential cell membrane area $\left(\mathrm{m}^{2}\right)$

$B_{D}$ Molecular diffusion coefficient $\left(\mathrm{kg} / \mathrm{m}^{2} \mathrm{sPa}\right)$

$B_{K n}$ The Knudsen coefficient $\left(\mathrm{kg} / \mathrm{m}^{2} \mathrm{sPa}\right)$

$B_{m}$ Membrane mass transfer coefficient $\left(\mathrm{kg} / \mathrm{m}^{2} \mathrm{sPa}\right)$

$C$ Thermal capacitance $\left(\mathrm{J} /{ }^{\circ} \mathrm{C}\right)$

$C_{\text {elc }}$ Electrical capacitance per unit length $(\mathrm{F} / \mathrm{m})$

$c_{p}$ Specific heat of water $\left(\mathrm{J} / \mathrm{kg}^{\circ} \mathrm{C}\right)$

$D$ Diffusivity of water vapor and air mixture $\left(\mathrm{m}^{2} / \mathrm{s}\right)$

$D_{h}$ Hydraulic diameter

$d z$ Differential length along flow direction $(\mathrm{m})$

$H_{v}[T]$ latent heat of vaporization at temperature $\mathrm{T}$ $(\mathrm{J} / \mathrm{kg})$

$h$ Heat transfer coefficient $\left(\mathrm{W} / \mathrm{m}^{2}{ }^{\circ} \mathrm{C}\right)$

I Electrical current Ampere (A)

$J$ Mass flux of distilled water $\left(\mathrm{kg} / \mathrm{m}^{2} \mathrm{~s}\right)$

$k$ Thermal conductivity $\left(\mathrm{W} / \mathrm{m}^{\circ} \mathrm{C}\right)$

L Thermal inductor

$M$ Mass flow rate $(\mathrm{kg} / \mathrm{s})$

$m_{w}$ Molecular mass of water $(\mathrm{kg} / \mathrm{mol})$

$P$ Vapor pressure $(\mathrm{Pa})$

$P_{a}$ The air pressure $(\mathrm{Pa})$

$P_{w}^{s a t}[T]$ Saturation vapor pressure of pure water at temperature $\mathrm{T}(\mathrm{Pa})$

$\operatorname{Pr}$ Prandtl number

$Q$ Heat transfer rate Watt $(\mathrm{W})[0.08 \mathrm{~cm}]$

$\bar{R}$ Gas constant $(\mathrm{J} / \mathrm{mol} \mathrm{K})$

$\mathrm{R}$ Thermal resistance $\left({ }^{\circ} \mathrm{C} / \mathrm{W}\right)$

$\mathrm{R}_{\text {eq }}$ Equivalent thermal resistance $\left({ }^{\circ} \mathrm{C} / \mathrm{W}\right)$

Re Reynolds number

$R_{\text {elc }}$ Electrical resistance per unit length $(\Omega / \mathrm{m})$

$T$ Temperature $\left({ }^{\circ} \mathrm{C}\right.$ or $\left.\mathrm{K}\right)$ 
$V$ Voltage Volt (V)

$v$ Differential cell volume $\left(\mathrm{m}^{3}\right)$

$x_{\mathrm{NaCl}}$ Molar fraction of $\mathrm{NaCl}$ salt

$Z$ Thermal impedance $\left({ }^{\circ} \mathrm{C} / \mathrm{W}\right)$

\section{Greek Symbols}

$\delta x$ Differential length $(\mathrm{m})$

$\delta$ Membrane thickness (m)

$\varepsilon$ Membrane porosity

$\xi$ Membrane tortuosity

$\rho$ Density $\left(\mathrm{kg} / \mathrm{m}^{3}\right)$

$\eta$ Dynamic viscosity

\section{Subscripts}

b Bulk

f Feed

g gas (air)

in Inlet

m Membrane

n Index for cell number

$\mathrm{N}$ Total number of cells

out Outlet

p Permeate

term Terminating

w Water in liquid phase

\section{Acknowledgment}

Research reported in this publication was supported by King Abdullah University of Science and Technology (KAUST).

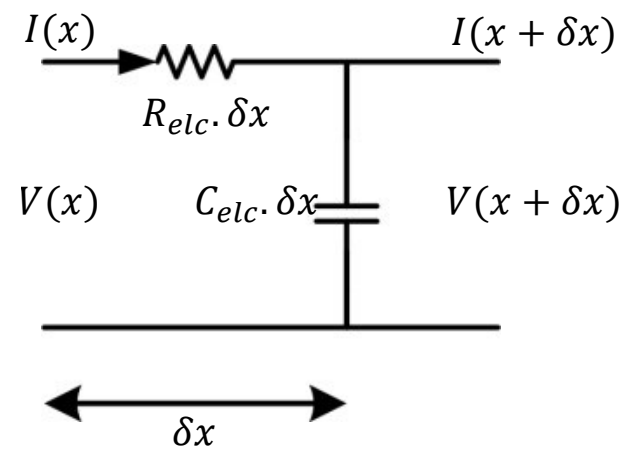

Figure A.18: A schematic diagram of a transmission line.

\section{Appendix A. Electrical analogues for thermal elements}

The analogy can be derived from the basic equations of electrical and thermal systems. Let's start by considering the one dimensional heat conduction through an element of cross sectional area $A_{c s}$ and thermal conductivity $k$ and thickness of $\delta x$, the heat transfer rate is given by the Fourier's law as:

$$
Q=-k A_{c s} \frac{\partial T}{\partial x} .
$$

The difference of heat transfer rates between two parallel surfaces is equal to the heat absorbed to raise the temperature of the control volume, as given by:

$$
\frac{\partial Q}{\partial x}=-\rho A_{c s} c_{p} \frac{\partial T}{\partial t} .
$$

Substituting (A.1) into (A.2) gives the one dimensional heat diffusion equation as:

$$
\frac{\partial T}{\partial t}=\frac{k}{\rho c_{p}} \frac{\partial^{2} T}{\partial x^{2}} .
$$

In order to complete the analogy, a section of a uniform transmission line is considered as depicted in Fig. A.18, where the line resistance and capacitance $\left(R_{\text {elc }}, C_{\text {elc }}\right.$ respectively) are given per unit length. For some length $\delta x$, the total resistance and capacitance are $R_{\text {elc }} \delta x$ and $C_{\text {elc }} \delta x$ respectively.

Ohm's law gives:

$$
V(x+\delta x)-V(x)=-I R_{\mathrm{elc}} . \delta x .
$$

Applying Kirchoff's current law gives:

$$
I(x+\delta x)-I(x)=-C_{\mathrm{elc}} \cdot \delta x \frac{\partial V}{\partial t} .
$$

Taking the limit as $\delta x \rightarrow 0$ of (A.4) and (A.5), respectively gives:

$$
I=-\frac{1}{R_{\text {elc }}} \frac{\partial V}{\partial x},
$$




$$
\frac{\partial I}{\partial x}=-C_{\mathrm{elc}} \frac{\partial V}{\partial t} .
$$

Combining equations (A.6) and (A.7) results in the telegraph equations:

$$
\frac{\partial^{2} V}{\partial x^{2}}=R_{e} C_{e} \frac{\partial V}{\partial t} .
$$

Comparing (A.6) with (A.1) and (A.7) with (A.2), leads to the analogy between electrical and thermal systems given in Table A.3.

\section{Appendix B. Electrical analogy to DCMD}

\section{Appendix B.1. Feeding and terminating the network}

The mass flow rate at the feed inlet $\left(M_{\mathrm{f}_{\mathrm{in}}}\right)$ supplies heat in (Watts) at the rate of:

$$
Q_{\mathrm{f}_{\mathrm{in}}}=M_{\mathrm{f}_{\mathrm{in}}} c_{p} T_{\mathrm{f}_{\mathrm{in}}} .
$$

Therefore, the input impedance of the network should be $1 /\left(M_{\mathrm{f}_{\mathrm{in}}} c_{p}\right)$ in order for a voltage of $T_{\mathrm{f}_{\mathrm{in}}}$ to develop at the feed input terminal of the network. On the feed outlet terminal, the rate of heat leaving the system is given by:

$$
Q_{\mathrm{f}_{\text {out }}}=M_{\mathrm{f}_{\text {out }}} c_{p} T_{\mathrm{f}_{\text {out }}} .
$$

Therefore, the network should be terminated in resistance of $1 /\left(M_{\mathrm{f}_{\mathrm{out}}} c_{p}\right)$ to develop a voltage of $T_{\mathrm{f}_{\mathrm{out}}}$ across the terminating resistance.

Similar argument can be made for the permeate side in order to properly feed and terminate the network. The feed and permeate inlet temperatures are manipulated by the voltage sources $\left(T_{\mathrm{f}_{\mathrm{in}}}\right.$ and $\left.T_{\mathrm{p}_{\mathrm{in}}}\right)$, respectively. Whereas the feed and permeate inlet mass flow rates are proportional to the heat transfer rates at module's inlets.

\section{Appendix B.2. The Series Impedance}

In order to simulate the temperature gradient along the membrane in both the feed and permeate sides, adjacent cells are coupled together via the series impedances $\left(\mathrm{Z}_{\mathrm{f}}^{\mathrm{n}}\right.$ and $\left.\mathrm{Z}_{\mathrm{p}}^{\mathrm{n}}\right)$. Careful analysis should be done to design them in order to obtain the correct temperature drop from one cell to the next. As stated in [24], this impedance cannot be determined by direct analogy. However, it is clear that the value of this impedance should be a function of mass flow rates on both feed and permeate sides and the energy lost/received to/from the other side of DCMD module, i.e. the thermal resistance at the membrane interfaces and through the membrane. From the analysis of the constant jacket temperature heat exchanger analogue in [24], and some intuition, the feed side network can be simplified as shown in Fig. B.19, where an equivalent shunt thermal resistance $R_{e q}$ is introduced. Both

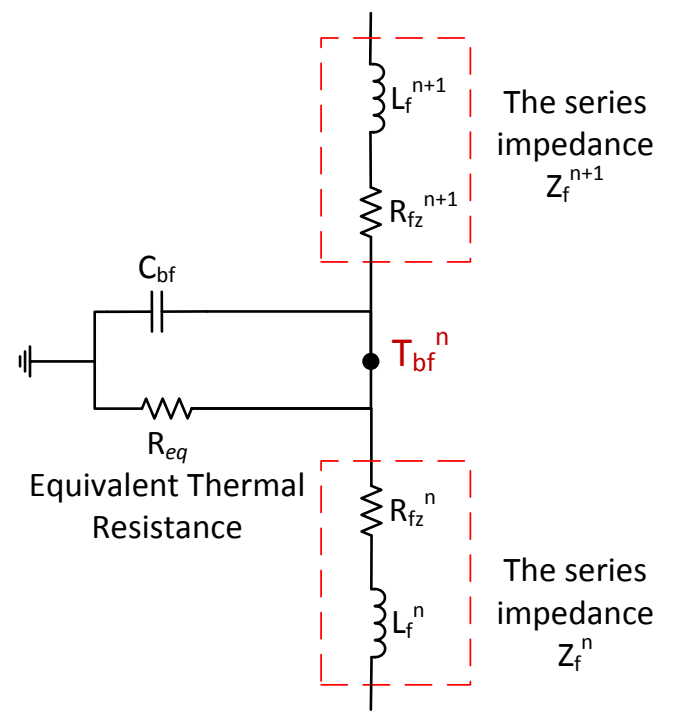

Figure B.19: Simplified Electrical analogue of the feed side.

the series impedance $Z_{f}^{n}$ and the shunt resistance $R_{e q}$ are unknown and to be identified empirically. It is apparent that the resistance $\mathrm{R}_{\mathrm{fz}}^{\mathrm{n}}$ is inversely proportional to $\mathrm{R}_{\mathrm{eq}}$ and the square of the mass flow rate $M_{\mathrm{f}_{\mathrm{n}}}$. The series resistance $\mathrm{R}_{\mathrm{fz}}^{\mathrm{n}}$ is to take the form reported in [24] as follows:

$$
\mathrm{R}_{\mathrm{fz}}^{\mathrm{n}}=\frac{1}{M_{\mathrm{f}_{\mathrm{n}}}^{2} c_{p}^{2} \mathrm{R}_{\mathrm{eq}}} .
$$

In order to achieve the correct response from the network, several values of the equivalent shunt thermal resistance $R_{\text {eq }}$ were tested and verified against experimental data. Based on that, the following parametrization was found to give the best result:

$$
\mathrm{Z}_{\mathrm{f}}^{\mathrm{n}}=\mathrm{R}_{\mathrm{fz}}^{\mathrm{n}}+j \omega \mathrm{L}_{\mathrm{f}}^{\mathrm{n}}
$$

where:

$$
\begin{aligned}
\mathrm{R}_{\mathrm{fz}}^{\mathrm{n}} & =\frac{1}{M_{\mathrm{f}_{\mathrm{n}}}^{2} c_{p}^{2}\left(\mathrm{R}_{\mathrm{f}}+\mathrm{R}_{\mathrm{m}}+\mathrm{R}_{\mathrm{p}}\right)} \\
\mathrm{L}_{\mathrm{f}}^{\mathrm{n}} & =\frac{\mathrm{R}_{\mathrm{fz}}{ }^{2} C_{\mathrm{bf}}}{4} .
\end{aligned}
$$

The same procedure was used to obtain the parametrization for the permeate side series impedance $\left(\mathrm{Z}_{\mathrm{p}}^{\mathrm{n}}\right)$ as:

$$
\mathrm{Z}_{\mathrm{p}}^{\mathrm{n}}=\mathrm{R}_{\mathrm{pz}}^{\mathrm{n}}+j \omega \mathrm{L}_{\mathrm{p}}^{\mathrm{n}}
$$

where:

$$
\begin{aligned}
& \mathrm{R}_{\mathrm{pz}}^{\mathrm{n}}=\frac{1}{M_{\mathrm{p}_{\mathrm{n}}}^{2} c_{p}^{2}\left(\mathrm{R}_{\mathrm{f}}+0.5 \mathrm{R}_{\mathrm{m}}+\mathrm{R}_{\mathrm{p}}\right)} \\
& \mathrm{L}_{\mathrm{p}}^{\mathrm{n}}=\frac{\mathrm{R}_{\mathrm{pz}}^{2} C_{\mathrm{bp}}}{4}
\end{aligned}
$$


Table A.3: Electrical analogues of thermal system

\begin{tabular}{l|c|c||l|c|c}
\hline \multicolumn{3}{c||}{} & \multicolumn{3}{c}{ Thermal } \\
\hline Element & Expression & Unit & Element & Expression & Unit \\
\hline Voltage & $V$ & $\mathrm{~V}$ & Temperature & $T$ & ${ }^{\circ} \mathrm{C}$ or K \\
Current & $I$ & $\mathrm{~A}$ & Heat transfer rate & $Q$ & Watt $(\mathrm{W}=\mathrm{J} / \mathrm{s})$ \\
Resistor & $R_{\text {elc }} \delta x$ & $\Omega$ & Resistor & $\frac{\delta x}{k A_{c s}}$ & ${ }^{\circ} \mathrm{C} / \mathrm{W}$ \\
Capacitor & $C_{\text {elc }} \delta x$ & $\mathrm{~F}$ & Capacitor & $C=c_{p} \cdot$ mass & $\mathrm{J} /{ }^{\circ} \mathrm{C}$ \\
\hline
\end{tabular}

Since heat is stored in the feed and permeate streams and transferred from one cell to the next by their movement, heat transfer along the flow direction is highly influenced by the flow inertia, which resists sudden changes to the flow momentum. Hence, it is important to consider the conservation of momentum in the MD modeling. Therefore, the inductive impedances $\left(\mathrm{L}_{\mathrm{fz}}^{\mathrm{n}}, \mathrm{L}_{\mathrm{pz}}^{\mathrm{n}}\right)$ serve as the thermal inertia of the system to resist any sudden changes in the flow momentum and converts potential energy stored in the thermal capacitor to kinetic energy transferred by the stream mass flow rate and vice versa. This oscillatory behavior is damped by the heat transfer resistance. The energy balance equations are completed by taking into consideration the thermal inductor.

\section{References}

[1] M. Khayet, T. Matsuura, Chapter 1 - introduction to membrane distillation, in: M. K. Matsuura (Ed.), Membrane Distillation, Elsevier, Amsterdam, 2011, pp. 1 - 16 .

[2] L. Francis, N. Ghaffour, A. A. Alsaadi, G. L. Amy, Material gap membrane distillation: A new design for water vapor flux enhancement, Journal of Membrane Science 448 (0) (2013) 240 - 247.

[3] H. Chang, G.-B. Wang, Y.-H. Chen, C.-C. Li, C.L. Chang, Modeling and optimization of a solar driven membrane distillation desalination system, Renewable Energy 35 (12) (2010) 2714 - 2722.

[4] Y.-D. Kim, K. Thu, N. Ghaffour, K. C. Ng, Performance investigation of a solar-assisted direct contact membrane distillation system, Journal of Membrane Science 427 (0) (2013) 345 - 364.

[5] A. Alkhudhiri, N. Darwish, N. Hilal, Membrane distillation: A comprehensive review, Desalination 287 (0) (2012) 2 - 18.

[6] A. Chafidz, S. Al-Zahrani, M. N. Al-Otaibi, C. F. Hoong, T. F. Lai, M. Prabu, Portable and integrated solar-driven desalination system using membrane distillation for arid remote areas in saudi arabia, Desalination 345 (0) (2014) 36 - 49.

[7] M. Qtaishat, T. Matsuura, B. Kruczek, M. Khayet, Heat and mass transfer analysis in direct contact membrane distillation, Desalination 219 (1-3) (2008) 272-292.

[8] V. Bui, L. Vu, M. Nguyen, Modelling the simultaneous heat and mass transfer of direct contact membrane distillation in hollow fibre modules, Journal of Membrane Science 353 (1-2) (2010) 8593.

[9] E. K. Summers, H. A. Arafat, J. H. Lienhard, Energy efficiency comparison of single-stage membrane distillation (MD) desalination cycles in different configurations, Desalination 290 (2012) 5466.

[10] T.-C. Chen, C.-D. Ho, H.-M. Yeh, Theoretical modeling and experimental analysis of direct contact membrane distillation, Journal of Membrane Science 330 (1-2) (2009) 279-287.

[11] H. J. Hwang, K. He, S. Gray, J. Zhang, I. S. Moon, Direct contact membrane distillation (DCMD): Experimental study on the commercial PTFE membrane and modeling, Journal of Membrane Science 371 (1-2) (2011) 90-98.

[12] Y. M. Manawi, M. Khraisheh, A. K. Fard, F. Benyahia, S. Adham, Effect of operational parameters on distillate flux in direct contact membrane distillation (dcmd): Comparison between experimental and model predicted performance, Desalination 336 (0) (2014) 110 - 120.

[13] H. Chang, S.-G. Lyu, C.-M. Tsai, Y.-H. Chen, T.W. Cheng, Y.-H. Chou, Experimental and simulation study of a solar thermal driven membrane distillation desalination process, Desalination 286 (2012) $400-411$.

[14] B. Bin Ashoor, H. Fath, W. Marquardt, A. Mhamdi, Dynamic modeling of direct contact 
membrane distillation processes, in: 11th International Symposium on Process Systems Engineering, 2012, pp. 170-174.

[15] F. Eleiwi, T. M. Laleg-kirati, Dynamic modeling and optimization in membrane distillation system, in: The 19th World Congress of the International Federation of Automatic Control, Cape Town, 2014, pp. 3327-3332.

[16] F. Eleiwi, N. Ghaffour, A. S. Alsaadi, L. Francis, T. M. Laleg-Kirati, Dynamic modeling and experimental validation for direct contact membrane distillation (dcmd) process, Desalination 384 (2016) $1-11$.

[17] R. Porrazzo, A. Cipollina, M. Galluzzo, G. Micale, A neural network-based optimizing control system for a seawater-desalination solar-powered membrane distillation unit, Computers and Chemical Engineering 54 (0) (2013) 79 - 96.

[18] A. Karam, T. Laleg-Kirati, Electrical thermal networks for direct contact membrane distillation modeling, in: Control Applications (CCA), 2014 IEEE Conference on, 2014, pp. 1563-1569.

[19] A. M. Karam, T. M. Laleg-kirati, Electrical thermal network for direct contact membrane distillation modeling and analysis.

URL http://repository.kaust .edu.sa/kaust/handle/10754/344181

[20] F. Lagan, G. Barbieri, E. Drioli, Direct contact membrane distillation: modelling and concentration experiments, Journal of Membrane Science 166 (1) (2000) 1 - 11.

[21] R. Schofield, A. Fane, C. Fell, Heat and mass transfer in membrane distillation, Journal of Membrane Science 33 (3) (1987) 299 - 313.

[22] K. W. Lawson, D. R. Lloyd, Membrane distillation, Journal of Membrane Science 124 (1) (1997) $1-25$.

[23] D. A. Nield, A. Bejan, Chapter 2 heat transfer through a porous medium, in: Convection in Porous Media, 4th Edition, Springer, 2013, pp. 31 $-46$.

[24] R. Ford, Electrical analogues for heat exchangers, Proceedings of the IEE - Part B: Radio and Electronic Engineering 103 (7) (1956) 65-82.

[25] A. Ferreira, S. Chen, M. Simaan, J. Boston, J. Antaki, A nonlinear state-space model of a combined cardiovascular system and a rotary pump, in: Decision and Control, 2005 and 2005 European Control Conference. CDC-ECC '05. 44th IEEE Conference on, 2005, pp. 897-902.
[26] A. Robertson, D. Gross, An electrical-analog method for transient heat-flow analysis, Journal of Research of the National Bureau of Standards 61 (2) (1958) 105.

[27] I. Fatt, A new electric analogue model for nonsteady state flow problems, AIChE Journal 4 (1) (1958) 49-52.

[28] L. Francis, N. Ghaffour, A. Alsaadi, S. Nunes, G. Amy, Performance evaluation of the demd desalination process under bench scale and large scale module operating conditions, Journal of Membrane Science 455 (0) (2014) 103 - 112.

[29] A. S. Alsaadi, L. Francis, G. L. Amy, N. Ghaffour, Experimental and theoretical analyses of temperature polarization effect in vacuum membrane distillation, Journal of Membrane Science 471 (0) (2014) $138-148$.

[30] MATLAB, version 8.0 (R2012b), The MathWorks Inc., Natick, Massachusetts, 2012. 